\title{
COMPETÊNCIAS GERENCIAIS E INOVAÇÃO: PERCEPÇÃO DE GESTORES DE MICRO E PEQUENAS EMPRESAS
}

lonete Moraes ${ }^{1}$

Angela Cristina Rocha De Souza ${ }^{1}$

Rafaela Maior ${ }^{1}$

Maria Iraê De Souza Corrêa ${ }^{1}$

${ }^{1}$ Universidade Federal Rural de Pernambuco 


\section{COMPETÊNCIAS GERENCIAIS E INOVAÇÃO: PERCEPÇÃO DE GESTORES DE MICRO E PEQUENAS EMPRESAS}

Resumo: Este estudo teve como objetivo identificar competências gerenciais relevantes para a inovação em micro e pequenas empresas. Trata-se de um aspecto importante visto ser a inovação um fator decisivo para a sobrevivência dessas empresas. $O$ estudo proposto por Quinn et al. (2003) sobre competências gerenciais serviu como lente na busca destas competências. É um estudo qualitativo de caráter exploratório e descritivo. Na coleta de dados utilizou-se entrevistas semiestruturadas, com cinco gestores e dois consultores. Os resultados mostraram que vinte e uma competências estão presentes no estudo de Quinn et al. (2003), sendo que duas competências foram alocadas em papéis gerenciais diferentes do que havia definido os autores. Cinco competências gerenciais, não contempladas pelos autores, emergiram, como por exemplo, saber lidar com erros e fracassos. Conclui-se que o desenvolvimento destas competências é um aspecto importante para que o gestor saiba lidar com os desafios e inconstâncias que a inovação pode proporcionar.

Palavras-chave: : Inovação. Competências. Gestores. Micro e pequenas empresas.

\section{Introdução}

A inovação tem sido considerada um fator decisivo para as organizações. Alguns autores a relacionam à sobrevivência e ao sucesso das empresas (Costa \& Olave, 2014), outros a associam à identificação de diferenciais competitivos para grandes e pequenas empresas (Tidd \& Bessant, 2013). A inovação torna-se ainda mais critica quando falamos das micro e pequenas empresas (MPE's), não apenas pela importância numérica, uma vez que representam $99 \%$ das empresas brasileiras, mas também pela relevância dessas empresas para o desenvolvimento social e econômico do país (Serviço Brasileiro de Apoio às Micro e Pequenas Empresas [SEBRAE], 2014). Como afirmam Neves, Santos e Silva (2011) e Almeida, Glória Júnior e Zouain (2007), as MPE's devem assumir uma postura estratégica mais propensa a inovar para que não sofram prejuízos ao seu desenvolvimento ou mesmo incrementem as taxas de mortalidade do setor.

É neste contexto que se observa o aumento do interesse pela compreensão do processo de inovação dentro das organizações tendo em vista seus múltiplos aspectos. Sob a perspectiva dos fatores internos desse processo, autores apontam a importância das habilidades e competências de gestores das organizações. Reichert, Camboim e Zawislk (2015), por exemplo, buscaram identificar as capacidades de inovação de empresas industriais brasileiras e, com isso, explicitar suas trajetórias de inovação. Já Ferigotti e Fernandes (2014) se detiveram na interação entre competências gerenciais e rotinas para o desempenho em inovação, junto a gerentes e líderes de projetos da Electrolux do Brasil S/A.

Autores como Mello, Machado e Jesus (2010) são enfáticos ao dizer que o poder da inovação se encontra na capacidade de integrar conhecimento com habilidades gerenciais.

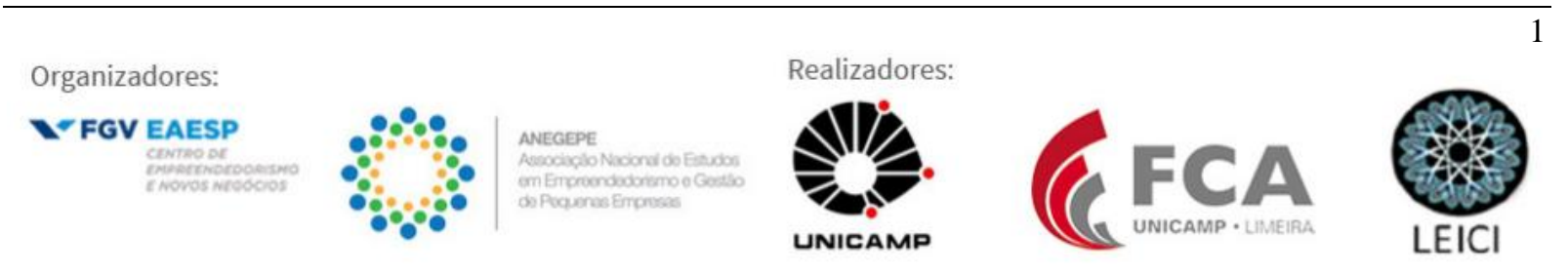


Ao mencionar a relevância da inovação nas MPE's, os referidos autores destacam a importância da construção de competências dos gestores, para a produção do bem ou serviço que se pretende disponibilizar no mercado.

Diferentes estudos, realizados no Brasil, têm contribuído para identificar as competências individuais e organizacionais que podem auxiliar os gestores a enfrentar os desafios que emergem frente à gestão de uma organização. Pode-se citar, por exemplo, o estudo de Picchiai (2008), que buscou descrever as competências necessárias aos profissionais que ocupam cargo de direção, numa instituição hospitalar. Estudos recentes, como o de Pena, Ferreira, Braga e Castanheira (2015) trouxeram contribuições importantes a respeito das competências que os líderes de turma, do curso de Administração, de uma Instituição de Ensino Superior, devem desenvolver para sua atuação enquanto líderes no contexto acadêmico e no mercado de trabalho. Já Paiva e Ferreira (2013) ao estudarem organizações do Triângulo Mineiro (MG) descreveram as competências necessárias aos gestores da área de Tecnologia da Informação (TI) e, Luciano, Becker e Testa (2012), por sua vez, as necessárias aos gestores sêniores de TI (CIOs) na região Sul do Brasil. Apesar dos resultados apresentados, os citados autores enfatizam a importância de mais pesquisas que possam ampliar o escopo para gestores de diferentes áreas, buscando fortalecer a base de conhecimentos sobre competências.

Desse modo, examinando os estudos sobre o tema, foi possível detectar uma lacuna no conhecimento acerca das competências necessárias para os processos inovativos em MPE's. Trata-se de um aspecto relevante visto ser a inovação um fator decisivo para a sobrevivência dessas empresas e a literatura nos mostra que as competências são importantes nos processos de inovação. Buscando trazer contribuições para essa lacuna, este artigo tem como questão de pesquisa: Quais competências gerenciais são relevantes para a inovação nas MPE's? Para responder à questão de pesquisa foi realizado um estudo qualitativo, utilizandose entrevistas semiestruturadas com cinto gestores de MPE's do estado de Pernambuco e dois consultores da área. É importante destacar que para identificar as competências relevantes para a inovação, este estudo optou por utilizar as vinte e quatro competências identificadas por Quinn, Thompson, Faerman e McGrath (2003) que são associadas a oito papéis gerenciais. Cada papel contempla três competências que permitem analisar a ação gerencial por meio de diferentes perspectivas, permitindo-se assim, se ter uma visão mais abrangente das competências que podem ser percebidas como relevantes para a inovação, pelos entrevistados.

Com este artigo, pretende-se contribuir para a consolidação de um corpo teórico de conhecimento que relacione competência, inovação e MPE's, permitindo que outros pesquisadores possam obter informações relevantes a sua pesquisa. Além disso, espera-se que tais informações auxiliem o fortalecimento da capacidade competitiva das MPE's, diminuindo sua mortalidade.

\section{Referencial Teórico}

\subsection{Competência}

O conceito de competência foi proposto pela primeira vez por David McClelland, em 1973, como uma característica individual, composta de três elementos: conhecimento,

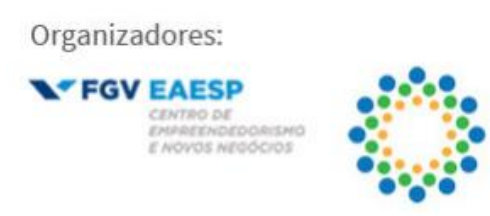

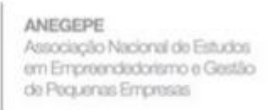

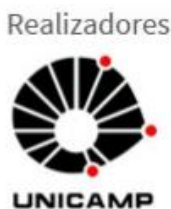


habilidade e atitude (CHA), que permitia justificar um bom desempenho em uma tarefa ou situação (Gloria Junior; Zouain, \& Almeida, 2014; Fleury \& Fleury, 2001). O elemento, contexto, foi abordado por Dutra, Hipólito e Silva (2000), para quem a competência é o desempenho profissional exercido por um indivíduo dentro dos objetivos organizacionais, isto é, suas realizações num determinado contexto.

É neste sentido que Sparrow e Bognanno (1994) explicam que não se pode falar de competência sem levar em consideração a dinâmica de uma organização e de seu contexto ao longo do tempo. Para os autores as competências possuem ciclos de vida, que são influenciados pelas inovações tecnológicas e pelas mudanças na estratégia das empresas. Nesta perspectiva, o caráter contextual das competências gerenciais passa a ser enfatizado. Para Le Boterf (2003) são os problemas, imprevistos e projetos que emergem no cotidiano das organizações que oportunizam a aprendizagem ou manutenção das competências profissionais. Conforme o autor, um profissional competente é aquele que sabe administrar uma situação de trabalho complexa, ou seja, é aquele indivíduo que a partir das adversidades é capaz de criar, reconstruir e inovar. Neste sentido, as competências são aprendidas no momento que a ação acontece e não existe ou pode ser observada antes dela. Desse modo, é a dinâmica organizacional, a qual os gestores estão submetidos, que cria a necessidade de desenvolvimento de competências por parte desses profissionais. Seguindo esta linha de pensamento Quinn et al. (2003) descreveram oito papéis gerenciais e suas respectivas competências que permitem analisar a ação gerencial por meio de diferentes perspectivas, como será apresentado a seguir.

\subsection{Competências Gerenciais segundo Quinn et al. (2003)}

Pode-se dizer que competência compõe um conceito de amplas visões e no âmbito desta pesquisa adotou-se como referência o estudo proposto por Quinn et al. (2003), em razão de sua abrangência, que permite analisar a ação gerencial, por meio da competência individual, em diversas direções, admitindo suportar a dinâmica do trabalho gerencial (Lima \& Aragão, 2014). No referido estudo, os autores identificaram quatro modelos de gestão distintos: relações humanas, processos internos, metas racionais, e sistemas abertos. Os modelos comportam oito papéis gerenciais - diretor, produtor, monitor, coordenador, mentor, negociador, facilitador e inovador - que envolvem certas competências particulares, conforme ilustra o Tabela 1.

No modelo das relações humanas, o foco da organização está no ambiente interno, na integração, na autonomia e na flexibilidade, podendo o gestor atuar como mentor e facilitador. O Mentor dedica-se ao aperfeiçoamento das pessoas através de uma orientação cuidadosa e de empatia, para isso ele precisa ter: compreensão de si mesmo e dos outros; comunicação eficaz e desenvolver os empregados. $\mathrm{O}$ argumento é que o envolvimento resulta em compromisso, e os valores centrais são a participação, resolução de conflitos e construção de consenso. Por sua vez, o Facilitador estimula o espírito de equipe e promove um processo decisório participativo, além de administrar conflitos.

No modelo dos processos internos, o foco da organização está no ambiente interno, na integração, no controle e na estabilidade, podendo o gestor atuar como coordenador e monitor. O Coordenador dá sustentação à estrutura e ao fluxo de sistema, precisando assim saber gerenciar projetos, fazer o planejamento de trabalho e fazer um gerenciamento

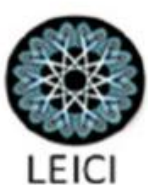


multidisciplinar. O Monitor deve acompanhar o que se passa em um setor, determinar se as pessoas estão cumprindo as regras e averiguar se tudo está saindo dentro do desejado. O papel de monitor requer competências de monitoramento do desempenho individual, gerenciamento do desempenho e processos coletivos e, também análise de informações com pensamento crítico.

No modelo de metas racionais, o foco da organização está no ambiente externo, na diferenciação, na estabilidade e no controle. Neste modelo, o gerente deve executar dois papéis: diretor e produtor. O Diretor apresenta atitudes objetivas e chama as responsabilidades para si ao definir problemas, desenvolver e comunicar uma visão, estabelecer metas e objetivos, e fazer todo o planejamento e organização. O Produtor, por sua vez, é orientado para tarefas, mantém o foco no trabalho e sustenta elevada produtividade, exibindo alta capacidade para motivar e gerenciar tempo e estresse.

Tabela 1

Os oito papéis gerenciais e suas respectivas competências-chave.

\begin{tabular}{|c|c|c|}
\hline Modelo & Papéis & Competências \\
\hline \multirow{2}{*}{ Relações Humanas } & Mentor & $\begin{array}{l}\text { - Compreensão de si mesmo e dos outros } \\
\text { - Comunicação eficaz } \\
\text { - Desenvolvimento dos empregados }\end{array}$ \\
\hline & Facilitador & $\begin{array}{l}\text { - Construção de equipe } \\
\text { - Uso do processo decisório participativo } \\
\text { - Administração de conflitos }\end{array}$ \\
\hline \multirow{2}{*}{ Processos internos } & Monitor & $\begin{array}{l}\text { - Monitoramento do desempenho individual } \\
\text { - Gerenciamento do desempenho e processos coletivos } \\
\text { - Análise de informações com pensamento crítico }\end{array}$ \\
\hline & Coordenador & $\begin{array}{l}\text { - Gerenciamento de projetos } \\
\text { - Planejamento de trabalho } \\
\text { - Gerenciamento multidisciplinar }\end{array}$ \\
\hline \multirow[t]{2}{*}{ Metas racionais } & Diretor & $\begin{array}{l}\text { - Desenvolvimento e comunicação de uma visão } \\
\text { - Estabelecimento de metas e objetivos } \\
\text { - Planejamento e organização }\end{array}$ \\
\hline & Produtor & $\begin{array}{l}\text { - Trabalho produtivo } \\
\text { - Fomento de um ambiente de trabalho produtivo } \\
\text { - Gerenciamento do tempo e do estresse }\end{array}$ \\
\hline \multirow[t]{2}{*}{ Sistemas abertos } & Negociador & $\begin{array}{l}\text { - Construção e manutenção de uma base de pode } \\
\text {-Negociação de acordos e } \\
\text { - Apresentação de ideias }\end{array}$ \\
\hline & Inovador & $\begin{array}{l}\text { - Convívio com a mudança } \\
\text { - Pensamento criativo } \\
\text { - Gerenciamento da mudança }\end{array}$ \\
\hline
\end{tabular}

Nota. Fonte: Adaptado de "Competências gerenciais: princípios e aplicações," de R. E. Quinn, M. Thompson, S. R. Faerman e M. Mcgrafth, M, 2003, p.25.

No último modelo, dos sistemas abertos, o foco da organização está no ambiente externo, na diferenciação, na flexibilidade e na autonomia, podendo o gestor atuar nos papéis de negociador e inovador. O Negociador preocupa-se com a sustentação da legitimidade 
exterior e a obtenção de recursos externos. Para este papel espera-se ter astúcia, capacidade de persuasão e influência. Já o Inovador facilita a adaptação e a mudança, baseando-se na indução, em ideias e em insights intuitivos. Este último papel, por sua vez, fundamenta-se na capacidade de adaptação e de resposta ao meio externo, envolvendo o uso da criatividade e o convívio e gerenciamento da mudança.

Como pode ser observado no Tabela 1, Quinn et al. (2003) relacionam três competências-chave a cada papel. Estas competências, se bem administradas, podem aportar contribuições únicas para a realização das estratégias de uma organização (Fernandes \& Comini, 2008). Fleury e Fleury (2001) declaram que tais competências resultam de um conjunto de aprendizagens sociais, que envolve descobertas e capacitações de recursos humanos. Ao mesmo tempo, Quinn et al. (2003) deixam claro em seu estudo, que este modelo e as competências relacionadas a cada um dos papéis encontram-se em permanente evolução. De acordo com os autores, à medida que mudam os valores da sociedade, alteram-se pontos de vista e assim podem surgir novos modelos e competências.

\section{Procedimentos Metodológicos}

Este estudo é de cunho qualitativo, de caráter exploratório e descritivo. Pesquisadores que optam por este viés metodológico, preocupam-se com o aprofundamento da compreensão e explicação das relações sociais, ou seja, buscam compreender como os indivíduos entendem o seu mundo e as experiências que vivenciam (Gerhardt \& Silveira, 2009). A seleção da amostra foi dividida em dois níveis - organização e indivíduo (Merriam, 2009). Foram selecionadas cinco empresas de Pernambuco, com base em dois critérios: ser classificada como MPE e ter desenvolvido algum tipo de inovação. Na Tabela 2 pode-se observar que, das cinco organizações investigadas, três são microempresas e duas empresas de pequeno porte. No que se refere à inovação, todas as empresas selecionadas apresentaram algum tipo de inovação. É importante esclarecer que em virtude do tempo destinado a realização desse estudo, optou-se por identificar e descrever apenas uma inovação de cada empresa. Por solicitação dos gestores entrevistados, seus nomes e os nomes das empresas não serão divulgados, tendo sido identificados por pseudônimos.

Tabela 2

Dados sobre as empresas e seus gestores

\begin{tabular}{llllc}
\hline Gestor & Empresa & $\begin{array}{l}\text { Classificação } \\
\text { da empresa }\end{array}$ & \multicolumn{1}{c}{ Inovação } & $\begin{array}{c}\text { Tipo de } \\
\text { Inovação }\end{array}$ \\
\hline Letícia & Ecoxiki & Micro & $\begin{array}{l}\text { Aplicação inovadora de produtos criados } \\
\text { manualmente através da reutilização de lixos. }\end{array}$ & Produto \\
\hline Diogo & $\begin{array}{l}\text { Creative } \\
\text { Mobile }\end{array}$ & Pequena & Achário - Aplicativo de moda. & Produto \\
\hline Edilson & Lavanderia 3M & Pequena & $\begin{array}{l}\text { Reaproveitamento da água utilizada na } \\
\text { lavagem de roupas. }\end{array}$ & Processo \\
\hline Guilherme & WG & Micro & $\begin{array}{l}\text { E.lac - Latícios Inteligentes -Software de } \\
\text { gestão de laticínios. }\end{array}$ & Produto \\
\hline Daniel & Phytogreen & Micro & $\begin{array}{l}\text { Uso da química verde para fabricação de } \\
\text { bioinseticida }\end{array}$ & Processo \\
\hline
\end{tabular}

Fonte: Elaborado pelas autoras.
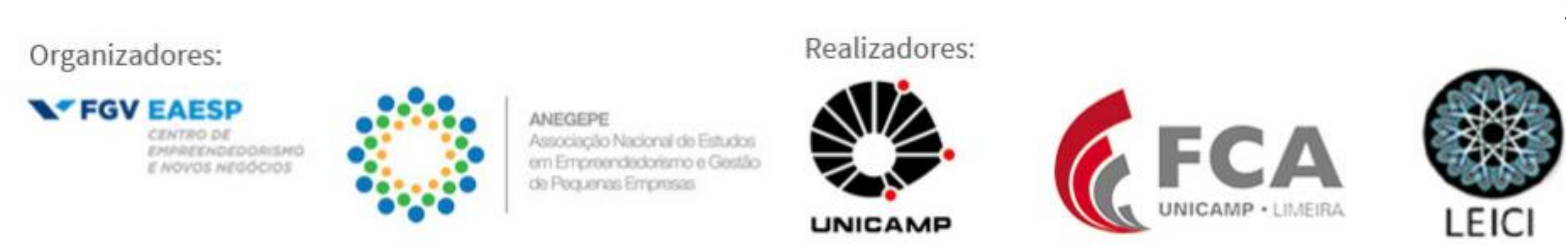
Com relação aos gestores entrevistados, o critério para seleção foi o envolvimento destes indivíduos no processo de inovação da empresa. Além dos gestores das empresas, também foram entrevistados dois consultores que trabalham diretamente com inovação: uma consultora do Núcleo de Gestão da Inovação - NAGI, e um consultor da Incubadora de Empresas de Base Tecnológica (INCUBATEC).

A coleta dos dados foi realizada por meio da entrevista semiestruturada. O roteiro foi elaborado tomando-se por base as competências gerenciais de Quinn et al. (2003). Entretanto, também foi permitido aos entrevistados indicar competências não contempladas no roteiro.

Seguindo as orientações de Merriam (2009), a análise dos dados iniciou-se com a primeira entrevista. Passou-se a identificar, por meio do relato dos entrevistados, as competências gerenciais consideradas relevantes para a inovação. Desse modo, foi criada uma lista de competências e conceitos que representassem a percepção, daquele entrevistado, sobre cada competência identificada. A estratégia do método consistiu em comparar o padrão de respostas entre os entrevistados e o referencial teórico, e posteriormente organizar os dados de modo a estarem alinhados aos objetivos específicos (Strauss \& Corbin, 2008).

\section{Resultados e Discussão}

De acordo com os dados coletados nesta pesquisa, várias competências gerenciais se destacaram como relevantes para a inovação dentro das MPE's. Dentre estas competências vinte e uma fazem parte do estudo de Quinn et al. (2003). Entretanto, algumas dessas competências, foram alocadas em papéis diferentes do que havia definido os autores. Além disso, cinco novas competências foram incluídas nos papéis gerencias.

\subsection{Competências Gerenciais Relevantes para a Inovação do modelo de Quinn et al. (2003)}

Dentre as vinte quatro competências do modelo de Quinn et al. (2003) vinte e uma foram destacadas como relevantes para a inovação. Entretanto, duas competências comunicação eficaz e desenvolvimento e comunicação de uma visão - foram alocadas em papéis diferentes do que havia definido os autores.

A competência comunicação eficaz, de acordo com os entrevistados não está relacionada ao papel de mentor, mas ao que Quinn et al. (2003) classificam como papel do negociador. Os gestores afirmam que a comunicação deve ser eficaz tanto em negociações com os clientes, como com os próprios funcionários dentro da empresa. Para Guilherme: "a comunicação é a fase mais difícil no relacionamento entre as pessoas, mas deve existir e chegar até a ser maçante (...) principalmente na pós-venda da nossa empresa". A consultora Ísis advoga que a comunicação é importante especialmente quando o gestor deseja comunicar a ideia que ele tem. Para explicar, a consultora retrata: "O desafio é tirar a inovação da mente e colocar no papel, o que envolve a comunicação. (...) Se você souber se comunicar a inovação destrincha [sic]".

Neste mesmo sentido, a comunicação eficaz relaciona-se diretamente com a apresentação de ideias. Sobre esta competência, Diogo afirma: "Aqui, geralmente a gente desenvolve uma ideia e se reúne para poder mostrar para a outra pessoa". Desta maneira, Diogo revela que a apresentação de ideias é uma competência significativa principalmente para o relacionamento entre os funcionários no momento em que se deseja transmitirr uma idealização. Por outro lado, Letícia conduz a relevância da apresentação de ideias para o
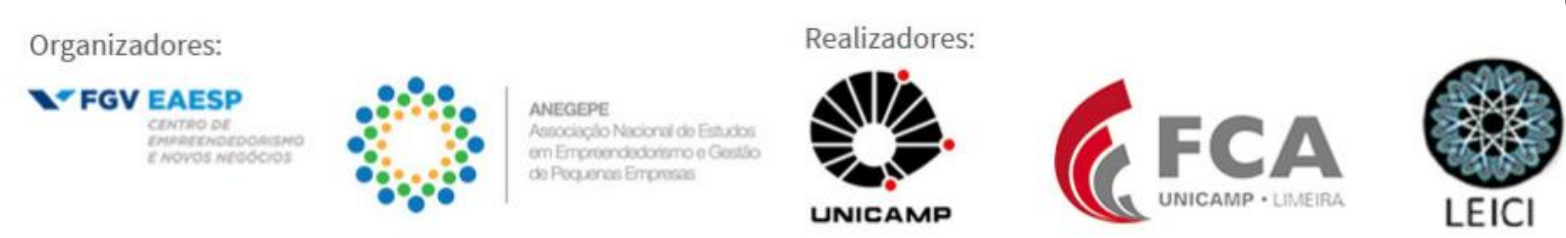
relacionamento entre empresa e clientes, onde a gestora afirma: "A apresentação é o mais importante, e aí vale usar tudo, todas as ferramentas que você tem".

Ainda foi possível perceber que os consultores e a maioria dos gestores atrelam a importância de uma comunicação eficaz e apresentação de ideias com o desenvolvimento e comunicação de uma visão, competência que foi direcionada por Quinn et al. (2003) ao papel do diretor, mas que neste estudo, atribuiu-se ao papel de negociador. A atribuição justifica-se frente às considerações dos gestores de que o desenvolvimento e comunicação de uma visão são aspectos relevantes para o momento de negociação com o cliente, no qual eles elaboram e comunicam as visões da empresa e dos seus produtos. Isto pode ser visto na fala de Letícia: "Tem que saber dizer [comunicar eficazmente] para o cliente de uma forma que gere um aprendizado para ele também. Então, por exemplo, se o cliente deseja que eu compre um material porque não é possível coletar, eu não faço. Só faço se for tirado do lixo". Por meio desta narrativa, a gestora procura explicar que é preciso comunicar aos clientes, durante o ato da negociação, as visões da organização.

No que se refere ao papel do mentor, apenas duas competências - compreender a si mesmo e aos outros e desenvolver os empregados foram destacadas como relevantes pelos entrevistados. Os gestores afirmam que conhecer seus próprios limites e a capacidade da sua equipe é importante para a implantação e gestão de uma inovação. João explica: "Para fazer a inovação você precisa se conhecer e principalmente conhecer os outros [funcionários]". Para os entrevistados, este conhecimento permite avaliar a contribuição que cada funcionário pode dar no processo de inovação. De acordo com Quinn et al. (2003), por mais que os membros de um grupo de trabalho tenham algo em comum, cada indivíduo também é único em algum sentido. Para os autores é importante que um gestor seja capaz de identificar as competências de cada funcionário para que possa aproveitá-las e estimulá-las da melhor forma possível. Além disso, é preciso saber desenvolver os empregados a fim de que se tornem cada vez mais habilidosos e eficientes e possam assim, ajudar no processo de inovação, como relata o Guilherme: "Isso é uma coisa que a gente investe muito (...), pois eles [os funcionários] são tão importantes como qualquer sócio da empresa". Percebe-se na fala dos entrevistados que os seus funcionários são parte importante na gestão de suas empresas. Entretanto, nenhum deles citou a competência uso do processo decisório participativo, que faz parte do papel do facilitador, como sendo relevante. Em explicação, os consultores elucidaram que não é comum a utilização de um processo decisório participativo por parte dos micro e pequenos empresários. Para os consultores o poder de decisão muitas vezes encontra-se unicamente na mão do gestor. Os funcionários trazem informações e ideias importantes, mas a palavra final fica na mão do gestor.

As competências construção de equipes e administração de conflitos, referentes ao papel do facilitador, também foram mencionadas como relevantes pela maioria dos entrevistados. No que se refere à construção de equipes os entrevistados percebem a importância de saber construir uma equipe e o quanto ela pode ser significativa para a empresa. Letícia, por exemplo, enfatiza a construção de equipes não só em sua empresa, mas também nos seus parceiros: "Ela é muito importante (...), a gente também ajuda os outros [indivíduos de parcerias feitas para eventuais projetos] a formarem suas equipes". Nesta mesma linha de pensamento o Guilherme afirma: "A formação de um time [equipe] é o que faz a empresa ser forte". De acordo com a fala dos entrevistados, uma equipe precisa ter

Organizadores:

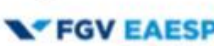

CENTEO of

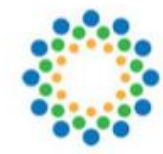
ANEGEPE

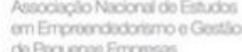

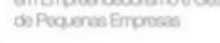
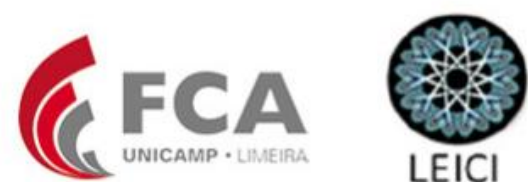
integração e estar motivada para conseguir atingir com eficácia as metas e objetivos da organização. Essa constatação fica evidenciada na fala dos consultores, como exemplifica o Felipe: "É preciso necessariamente ter uma equipe bem motivada e voltada para aquele propósito [inovação]".

Com relação ao papel do monitor, as competências gerenciamento do desempenho e processos coletivos e análise das informações com pensamento crítico foram destacadas pela maioria dos entrevistados. A primeira permite gerenciar o andamento do trabalho e identificar possíveis problemas no processo de desenvolvimento do produto. Esse gerenciamento passa pelas reuniões que eles fazem, onde procuram discutir as atividades da empresa, como observado na fala da Letícia: “(...) agente se reúne e diz o que tá dando certo e o que não tá dando certo a gente troca [realiza mudanças], isso precisa acontecer”. Além das reuniões os gestores relataram que esse gerenciamento também ocorre por meio de algumas ferramentas, como explica o Guilherme: “(...) hoje a gente tem ferramentas, software e controles que monitoram isso". Para que esse monitoramento ocorra, é importante que os gestores sejam capazes de fazer uma análise crítica das informações, como enfatiza o Diogo: "É sempre importante analisar as informações criticamente, questionando tudo". $\mathrm{Na}$ visão dos gestores a análise crítica serve para validar as decisões tomadas, como disse o Guilherme: "A análise crítica é uma validação do que você tá fazendo". Essa análise, segundo a maioria dos entrevistados, gera resultados positivos para a organização e prova que o gestor está seguindo o caminho certo, sendo ela importante em todas as fases da inovação, como explicado pela Isís: "Analisar as informações com pensamento crítico é necessário porque quando a ideia inovadora vem para o papel, tem que ter uma análise critica para saber fazer bem o uso dos recursos". A competência monitoramento do desempenho individual, que faz parte do papel de monitor, não foi vista como relevante pelos entrevistados. A explicação trazida pelos entrevistados é que as atividades são construídas em equipe, não tendo necessidade desse acompanhamento.

Todas as competências relacionadas ao papel do coordenador - gerenciamento de projetos, planejamento de trabalho e gerenciamento multidisciplinar - foram tidas como relevantes para a inovação. Para os gestores não tem como falar de forma separada das competências gerenciamento de projetos, planejamento do trabalho e planejamento e organização. Essa última atribuída, por Quinn et al. (2003), ao papel de diretor. Para os entrevistados estas competências estão interligadas. Desse modo, optou-se for falar das três sem separá-las.

A competência de gerenciamento de projetos é vista como um exercício de rotina pelos gestores, sendo importante para o sucesso de um empreendimento. O Daniel destaca sua importância ao dizer: "Tudo na vida é um projeto (...). Tem que usar as ferramentas que você tem disponível, fazer um planejamento baseado na situação real”. Essa visão dos gestores fica mais clara quando a Letícia explica: "O gerenciamento de projetos é bem importante porque a gente tá o tempo todo tomando decisões diferentes para cobrir [atingir] os objetivos". Ou seja, caso esse gerenciamento e controle não ocorram, os projetos podem não alcançar as expectativas dos gestores. Essa visão é reforçada pelos consultores, onde o Felipe afirma: "Gerenciar projetos é realmente fundamental (...) porque se você não tiver um gerenciamento você fatalmente não vai ter o sucesso desejado no desenvolvimento da inovação".

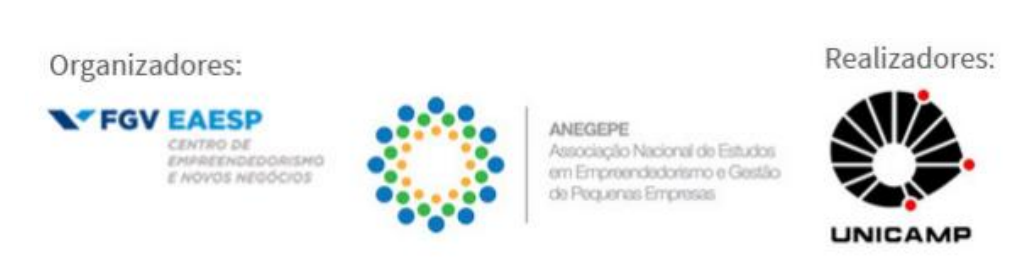

UNICAMP

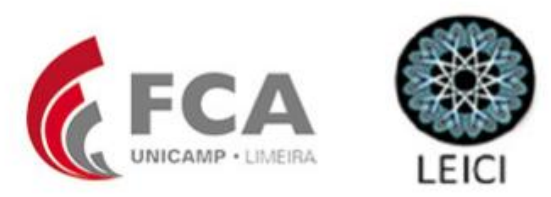


Diretamente relacionado com o gerenciamento de projetos, conforme os entrevistados, surgem o planejamento de trabalho e planejamento e organização. Para os gestores, essas competências são importantes para nortear o desenvolvimento de seus trabalhos e produtos e, ao mesmo tempo, serve para controlar suas atividades visando atingir os objetivos da organização. O Daniel enfatiza a importância ao dizer: "O planejamento precisa ser mais eficiente do que até a própria execução". Os entrevistados ainda dizem que ter organização e um bom planejamento pode possibilitar uma inovação com mais chances de acerto, como visto na fala do Edilson: "Se a pessoa que for inovar não for organizada, não vai funcionar". Para o Felipe os gestores precisam "encarar a inovação como algo que tem risco e que precisa ter um planejamento prévio para encarar esses riscos". Quinn et al. (2003) diz que quanto mais dinâmica for uma empresa, maior planejamento e organização ela demanda.

Ainda sobre o papel do coordenador, os entrevistados destacam a competência gerenciamento multidisciplinar, a qual se refere à administração de funções diversas dentro da organização (Quinn et al., 2003). Ao falar sobre esta competência, Guilherme explica que é importante entender de outras áreas, tais como, a contabilidade, para que o gestor possa progredir, principalmente quando se trata dos primeiros anos da empresa. Conforme os gestores, isto ocorre em virtude da necessidade de colocar a ideia inovadora em prática. Ísis também afirma que esta é uma competência importante: "Tem aquele básico [Recursos Humanos, Área de Finanças, Marketing e Operacional] e tem que ser isso. (...) Se for esse lance mais básico, tem que ter, senão não sai nem a inovação". Quinn et al. (2003) ressaltam que as empresas mais bem-sucedidas são aquelas onde os gestores apresentam esforços concomitantes, isto é, apresentam multidisciplinaridade em seu gerenciamento.

As competências do papel do produtor - fomento de um ambiente produtivo, trabalho produtivo e gerenciamento do tempo e do estresse - foram mencionadas pela maioria dos entrevistados. Sobre o trabalho produtivo, os entrevistados tiveram opiniões que corroboram com o relato do Daniel: "Pra mim é a mesma coisa, trabalho e produção. Só é trabalho se for produtivo (...) tem que ter eficiência". Ficou claro no relato dos gestores que 'trabalho produtivo' é um termo até redundante, uma vez que não conseguem imaginar trabalho sem produtividade. Sobre o fomento a um ambiente de trabalho produtivo, a fala do Edilson exemplifica o pensamento dos entrevistados sobre a importância dessa competência e diz como é realizada em sua empresa: "Você tem que fomentar com incentivos, com recompensas". Os incentivos e recompensas a que os gestores se referem envolvem, por exemplo, o que foi relatado pelo Diogo: "Ter um ambiente onde todo mundo possa estar relaxado e descontraído (...) o horário flexível também ajuda". Quinn et al. (2003) acredita que o fomento a um ambiente de trabalho produtivo está relacionado com a capacidade de um funcionário estar motivado a ser produtivo. Os consultores também defendem a relevância da produtividade na organização, assim como fomentá-la de algum modo.

Acerca do gerenciamento do tempo e do estresse Letícia relata que: "Nós [gestores] temos que estar sempre atentos a isto (...) hoje, por exemplo, em menor tempo consigo ser mais produtiva e cada vez mais me estresso menos". Na visão de Felipe: "o estresse é algo que acomete a todos nós, e, além disso, controlar o tempo é ainda um grande desafio para nós [enquanto gestores]". Ou seja, a preocupação com o tempo e o estresse é inevitável no trabalho de um empreendedor, e, portanto, é importante administrá-los. Quinn et
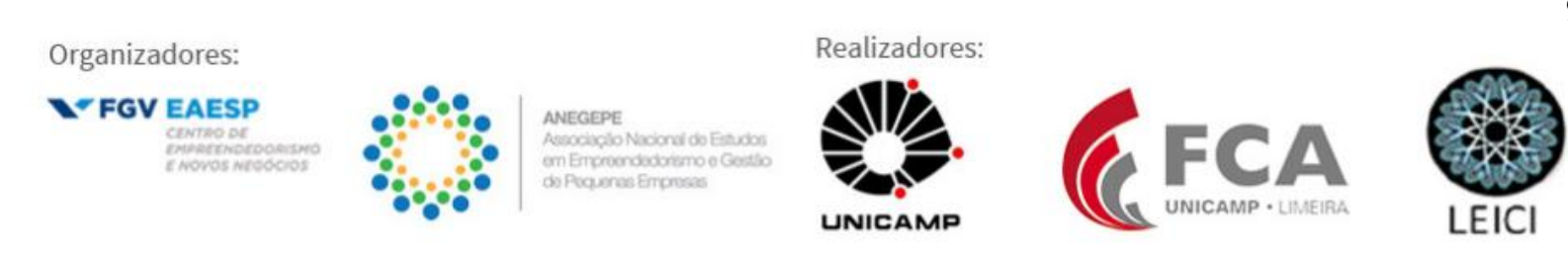
al. (2003) ao falar sobre o gerenciamento do tempo, salientam que os gestores precisam saber controlar eficientemente seu tempo e devem ter pausas revigorantes que possam amenizar o estresse.

A negociação de acordos e compromissos, atribuída por Quinn et al. (2003) ao papel do negociador, mencionada pela maioria dos gestores, e considerada uma exigência por alguns entrevistados. Para Daniel, "interagir com várias instituições, firmar parcerias com órgãos, para conseguir fazer as pesquisas" é importante, pois, de acordo com o empresário, "sem isso é basicamente inviável fazer os preparos todos, isto é, inovar". Sob o ponto de vista da consultora Ísis, a inovação demanda estas negociações. Quinn et al. (2003) reiteram que grandes decisões ocorrem por meio de negociações e, neste sentido, o diálogo exerce um papel vital para uma negociação eficaz. Já a competência construção de uma base de poder não foi vista como relevante pelos entrevistados. De acordo com os consultores, esta percepção dos gestores pode ser em virtude do tamanho das empresas e de ser voltadas para inovar, como explica Ísis: "Eles estão preocupados em construír equipe eficientes, que coloquem os projetos pra frente. Essa coisa de base de poder, talvez ocorra mais na frente [quando as empresas crescerem] (...) nessa fase não há tempo para isso, sabe.”

De acordo com os entrevistados, todas as três competências - convívio com a mudança, gerenciamento da mudança e pensamento criativo - referentes ao papel do inovador foram consideradas relevantes pelos entrevistados. A competência de convívio com a mudança faz parte de todo o processo inovador. O Daniel relata que a mudança ocorre de forma contínua: "Só existe mudança nessa história [processo de inovação] (...), é importante e faz parte integral [está presente em todo o processo] (...) não tem como inovar sem mudança”. Essa ideia é corroborada pelo Felipe : "A gente não consegue pensar em inovação sem vislumbrar essa questão da mudança". Como foi exposto pelos entrevistados, Quinn et al. (2003) também alega que a mudança ocorre constantemente na vida organizacional e que conviver e adaptar-se a ela é uma tarefa difícil, porém necessária. Evidencia-se assim, a importância de saber conviver com a mudança, entretanto, apenas sua aceitação não é suficiente para inovar, é preciso também saber gerenciá-la. Esse gerenciamento não é fácil de ser feito, evidenciando a necessidade dos gestores saberem lidar com as transformações. Letícia diz que esse gerenciamento promove a adaptação da sua empresa com as mudanças: "A gente procura se adaptar o tempo inteiro com o que acontece lá fora, aos nossos clientes".

Quanto a competência pensamento criativo, todos os entrevistados afirmam que a criatividade está presente em todos os momentos, sendo importante para o empreendedor que quer seguir o ramo da inovação. Edilson confirma essa afirmação ao frisar: "Todos nós somos criativos". Na fala do Daniel é possível reconhecer que o pensamento criativo faz parte do dia a dia dos gestores, envolvendo as atividades cotidianas: "É muito importante, pois a criatividade é forçada todo dia, desde ter que criar o nome, design (...), faz parte da vida do empreendedor". Percebe-se aqui como esta competência é importante para a inovação.

De modo geral, foi possível perceber que muitas das competências ilustradas por Quinn et al. (2003) foram consideradas relevantes, por parte dos entrevistados, no processo de inovação. No entanto, diferente dos resultados encontrados por Paiva e Ferreira (2013), Luciano et al. (2012), Fernandes (2012) e Picchiai (2008), algumas competências foram realocadas em relação aos papéis, além disso, algumas não foram citadas. Considera-se que

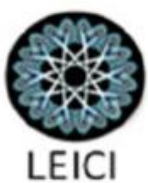


tal resultado relaciona-se ao contexto onde foi realizada a pesquisa, ou seja, MPE's inovadoras.

Picchiai (2008), por exemplo, utilizando o modelo de Quinn et al. (2003) para estudar as competências percebidas por gestores de um hospital, detectou que as competências relacionadas aos papéis de monitor, coordenador, diretor, produtor e negociador são menos percebidas e praticadas no todo. Já as competências mais valorizadas estão relacionadas aos papéis de inovador e mentor. A autora também identificou que as competências gerenciais menos percebidas e valorizadas pelos gestores do hospital foram: coordenação de projetos, análise das informações com pensamento crítico, desenvolvimento e comunicação de uma visão e fomento a um trabalho produtivo. De acordo com a autora, a percepção dos gestores quanto a importância dos papéis e competências ocorre em virtude de ser um hospital público, de alta complexidade, com fragmentação de atividades, uma estrutura muito departamentalizada, onde os controles e resultados acabam se diluindo. $\mathrm{O}$ que difere do presente estudo que investigou gestores de MPE's que desenvolveram inovação dentro da empresa. Em virtude deste fato, estas competências, foram vistas como relevantes quando relacionadas à inovação, pelos entrevistados. De acordo com a análise dos dados, a coordenação de projetos, por exemplo, é vista como um exercício rotineiro por parte dos gestores. Para os entrevistados, suas atividades giram em torno de um projeto e de sua gestão. Já a análise critica das informações permite ao gestor perceber se está seguindo o caminho certo, sendo ela importante em todas as fases da inovação.

Dessa forma, é possível constatar que as competências gerenciais desenvolvidas pelos gestores podem mudar diante do porte das empresas e das atividades que os gestores estão envolvidos no seu dia a dia. O que também enfatiza a quantidade de competências que um gestor precisa desenvolver, principalmente os de MPE's, por serem eles os responsáveis diretos para que a inovação aconteça em suas empresas.

\subsection{Competências Relevantes para a Inovação não Contempladas no por Quinn et al. (2003)}

De acordo com os dados coletados, surgiram cinco competências não contempladas por Quinn et al. (2003) e que na análise dos dados foram inseridas nos papéis gerenciais, conforme mostra a Tabela 3. Os próprios autores consideraram que “ (...) de quando em quando é importante reavaliar quais são as competências mais importantes para as atuais tendências das organizações" (2003, p.VII). Vale ressaltar ainda, que este estudo pretendeu investigar as competências gerenciais relevantes para a inovação em MPE's, trazendo assim, um direcionamento específico em relação a outras pesquisas já realizadas.

A primeira competência mencionada pelos entrevistados foi o conhecimento técnico sobre os produtos. Todos os gestores destacaram que não seria possível criar algo ou modificá-lo, sem conhecer suas propriedades e características. A entrevistada Letícia, por exemplo, afirma que precisa entender quais as peculiaridades de sua matéria-prima (materiais reutilizáveis) para que possa proceder da melhor maneira. Nesta mesma linha de pensamento, Edilson afirma: "Tem que ter [o conhecimento], você não pode abrir mão disso se não é doidice. Vamos separar doidice de inovação (...) você tem que ter o conhecimento técnico". Falando sobre isto, a consultora Ísis afirma: "Trabalhei com pessoas que tinham formação

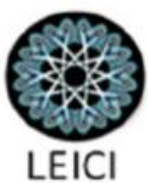


técnica na área, então notei que esse conhecimento técnico contribui para que o processo da inovação se desenvolva". Percebe-se assim, sua importância para a inovação.

Tabela 3

Competências gerenciais relevantes para a inovação.

\begin{tabular}{|c|c|c|}
\hline Modelo & Papéis & Competências \\
\hline \multirow{2}{*}{ Relações humanas } & Mentor & $\begin{array}{l}\text { - Compreensão de si mesmo e dos outros } \\
\text { - Desenvolvimento dos empregados }\end{array}$ \\
\hline & Facilitador & $\begin{array}{l}\text { - Construção de equipe } \\
\text { - Administração de conflitos }\end{array}$ \\
\hline \multirow[b]{2}{*}{ Processos internos } & \multirow[b]{2}{*}{ Coordenador } & $\begin{array}{l}\text { - Gerenciamento do desempenho e processos coletivos } \\
\text { - Análise de informações com pensamento crítico }\end{array}$ \\
\hline & & $\begin{array}{l}\text { - Gerenciamento de projetos } \\
\text { - Planejamento de trabalho } \\
\text { - Gerenciamento multidisciplinar }\end{array}$ \\
\hline \multirow[b]{2}{*}{ Metas racionais } & Diretor & $\begin{array}{l}\text { - Estabelecimento de metas e objetivos } \\
\text { - Planejamento e organização }\end{array}$ \\
\hline & Produtor & $\begin{array}{l}\text { - Trabalho produtivo } \\
\text { - Fomento de um ambiente de trabalho produtivo } \\
\text { - Gerenciamento do tempo de do estresse }\end{array}$ \\
\hline \multirow[b]{2}{*}{ Sistemas abertos } & Negociador & $\begin{array}{l}\text { - Negociação de acordos e compromissos } \\
\text { - Apresentação de ideias } \\
\text { - Desenvolvimento e comunicação de uma visão } \\
\text { - Comunicação eficaz }\end{array}$ \\
\hline & Inovador & $\begin{array}{l}\text { - Convívio com a mudança } \\
\text { - Pensamento criativo } \\
\text { - Gerenciamento da mudança } \\
\text { - Saber lidar com erros e fracassos } \\
\text { - Compreensão dos impactos da inovação } \\
\text { - Priorizar a utilização de recursos disponíveis } \\
\text { - Conexão da inovação com a estratégia da empresa } \\
\text { - Conhecimento técnico sobre seus produtos }\end{array}$ \\
\hline
\end{tabular}

Fonte: Elaborado pelas autoras. Adaptado de Quinn et al. (2003, p. 25).

A outra competência citada pelos entrevistados foi saber lidar com erros e fracassos. Para os gestores isto faz parte do dia a dia daqueles envolvidos com inovação e que os erros e os fracassos possibilitam o crescimento pessoal e profissional de um gestor inovador, como explica o Daniel:

Inovação e errar andam juntos. Você não pode inovar sem errar, faz parte integral [faz parte do processo de inovação](...). Não pode ter medo de erros e fracassos, eles fazem parte. Você vai melhorando a partir do momento que você aprende com os erros (...) ninguém tem condição de saber tudo, tem que estar preparado para fracassar e aprender a limitar esses fracassos (...) e estar ciente dos riscos.

Os consultores corroboram essa visão como relatado por Ísis: "Eu percebi na minha vida prática que os gestores precisam encarar a inovação como algo que tem risco e que precisa ter um planejamento prévio para encarar esses riscos e erros como parte importante do processo [de inovação]". 
Os gestores também concordaram que ter compreensão dos impactos da inovação é muito importante. Para os gestores, ter essa compreensão é importante para inovar e, além disso, esses impactos precisam ser mostrados para quem será de alguma forma afetado, como diz o Guilherme: “(...) tem que saber mostrar esses impactos [aos funcionários e clientes] (...) não adianta você inovar e não compreender esses impactos". Além disso, para os entrevistados, ter essa compreensão permite visualizar que os impactos podem ser positivos ou negativos para a empresa, como descreveu o Diogo: "É importante conseguir perceber isso [os impactos e as consequências] (...) tem que ter total noção desse impacto (...) ele pode ser positivo por um lado e negativo por outro [para a empresa]".

Ao retratar a relevância de saber inovar a partir dos recursos disponíveis, todos os gestores explicam que a inovação pode ocorrer com base naquilo que está acessível à organização. Daniel, no entanto, necessitaria de muitos recursos financeiros para desenvolver seu produto inovador, porém ele explica: "Eu utilizo equipamentos caros de outras entidades, mas se eu me limitasse e achasse que só estavam disponíveis recursos que fossem, de fato, meus, ficaria difícil inovar". Ou seja, apesar das aparentes inviabilidades, ele buscou novas fontes e alternativas e inovou a partir dos recursos que ele poderia ter acesso. O Diogo diz: "Tem que saber usar os recursos que você tem, não adianta você querer inovar se você não tem como botar ela em prática (...) tem que ter pé no chão". Segundo a consultora Ísis, "é necessário sempre inovar sem problematizar dentro da empresa, porque se não, a inovação fica aprisionada dentro das dificuldades, porque se ele [gestor] não parte dos recursos necessários, fica difícil". Felipe, em consenso, finaliza afirmando que "às vezes o gestor identifica que precisa de um recurso maior, mas se você for à essência do negócio você pode fazer mais com menos".

De acordo com os entrevistados, a inovação é importante para a inserção da empresa no mercado, desse modo, é preciso que ela tenha essa conexão com a estratégia da empresa. O Guilherme confirma essa visão ao dizer que: "É importante, porque a gente percebeu que se todas as nossas abordagens [estratégias e projetos] não tivessem a pegada inovadora a gente não ia conseguir entrar no mercado". O Daniel revalida ao dizer: "Nunca deixei de tentar [ter a conexão] (...) porque inovação é algo que não pode parar (...) quem consegue avançar mais rápido é quem ganha". Intensificando a opinião dos gestores, a Isís, explica:

É importante saber conectar a inovação com a estratégia, porque senão ela fica só em tentativas e se não houver essa conexão a inovação vai desperdiçar recursos, desperdiça[r] tempo, gera[r] frustração e corrobora[r] aquele estigma de que inovação é só para as grandes, só para quem tem dinheiro, só para quem tem equipe formada.

Diante do relato dos entrevistados, ao longo do texto, percebe-se que os gestores de MPE's que trabalham com o processo inovativo precisam desenvolver um conjunto de competências que podem auxiliar o seu gerenciamento. Convém ressaltar que estas competências são dinâmicas e que emergem na vida dos gestores à medida que vão se deparando, no seu dia a dia, com situações que exigem, o desenvolvimento das mesmas.

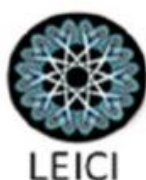




\section{Considerações Finais}

Por meio da análise dos dados foi possível concluir que, várias são as competências gerenciais, percebidas pelos gestores, como relevantes para a inovação no seu cotidiano de trabalho. Dentre estas, vinte e uma fazem parte do modelo proposto por Quinn et al. (2003) e estão ligadas a diferentes papéis que um gestor deve desenvolver para alcançar eficiência e eficácia no seu trabalho. Isto indica que, para a maior parte dos entrevistados, o desenvolvimento destas competências é um aspecto significante para que o gestor saiba lidar com os desafios e inconstâncias que a inovação pode proporcionar.

É importante destacar que algumas destas competências puderam ser relacionadas a papéis gerenciais diferentes dos abordados por Quinn et al. (2003). Para exemplificar, a competência comunicação eficaz relacionou-se, neste estudo, ao papel do negociador, uma vez que foi possível concluir que os gestores vêem esta competência especialmente no momento de negociação do seu produto ou ideia, seja com clientes ou entre os próprios funcionários. Ao mesmo tempo, algumas competências não foram percebidas como relevantes para a inovação, como construção e manutenção de uma base de poder, uso do processo decisório participativo e monitoramento do desempenho individual.

Também foi possível identificar cinco competências gerenciais que não estavam contempladas nos papéis gerencias propostos pelos autores e se apresentaram relevantes para a inovação, como: ter conhecimentos técnicos sobre seus produtos; saber lidar com os erros e fracassos; fazer a conexão da estratégia da empresa com a inovação; ter conhecimento dos impactos da inovação; e saber priorizar a utilização dos recursos disponíveis. Este resultado pode ser entendido a partir das especificidades relacionadas ao presente estudo que foi desenvolvido junto a pequenas e médias empresas e com foco em competências voltadas à inovação.

De modo geral, foi possível constatar que todas estas vinte e seis competências, desenvolvidas pelos gestores no seu cotidiano, são importantes para a inovação. Estas por sua vez contribuem para o surgimento de ideias inovadoras e também de uma gestão mais eficiente. Pode-se então, enfatizar que tais competências colaboram para direcionamentos comportamentais futuros dos gestores, uma vez que, a partir delas, eles aprenderão a lidar mais facilmente com situações que envolvem inovação.

Portanto, os resultados desta investigação ampliam a literatura disponível sobre inovação, competência e MPE's. No entanto, frente à complexidade dos assuntos aqui investigados, entende-se que muito ainda se tem a investigar a respeito desse assunto. Como o próprio Quinn et al. (2003) enfatiza, vivemos em um mundo dinâmico, e a natureza do trabalho gerencial precisa evoluir em decorrência das diversas transformações que ocorrem no ambiente interno ou externo à organização.

Finalmente, recomenda-se que novos estudos possam investigar essa temática tão importante para a sobrevivencia das MPE's, buscando empresas de outros setores e de empresas que se encontram incubadas.

\section{Referências}

Almeida, G. O., Gloria Junior, O. S., \& Zouain, D. M. (2014). Competências e habilidades relevantes para um chefe de unidade descentralizada de perícia da polícia federal. $R A M$ Revista de Administração Mackenzie, 15(4), 15-46.
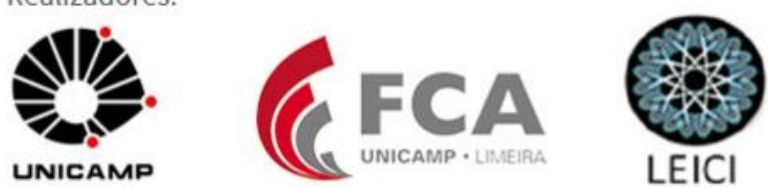
Costa, M. de S., \& Olave, M. E. L. (2014, março). Inovação em micro e pequenas empresas: uma visão dos agentes locais de inovação do Sebrae em Aracaju-SE. Anais do Encontro de Estudos em Empreendedorismo e Gestão de Pequenas Empresas, Goiânia, GO, Brasil, 8.

Dutra, J. S., Hipólito, J. A. M., \& Silva, C. M. (2000). Gestão de pessoas por competências: o caso de uma empresa do setor de telecomunicações. RAC-Revista de Administração Contemporânea, 4(1), 161-176.

Ferigotti, C., \& Fernandes, B. (2014). Competências gerenciais e capacidade para inovação: o caso da Electrolux do Brasil S/A. Revista de Administração e Inovação, 11(1), 73-96.

Fernandes, A. C. B. C. (2012). Competências gerenciais de enfermeiros de uma instituição hospitalar de Belo Horizonte. Dissertação de Mestrado em Administração, Faculdade Novos Horizontes, Belo Horizonte, MG, Brasil.

Fernandes, B. H. R., \& Comini, G. (2008, setembro). Limitações na estruturação de modelos de gestão por competências: uma análise de organizações líderes em diversos setores. Anais do Encontro da Associação Nacional de Pós-Graduação e Pesquisa em Administração EnANPAD, Rio de Janeiro, RJ, Brasil, 32.

Fleury, M. T. L., \& Fleury, A. (2001). Construindo o conceito de competência. RACRevista de Administração Contemporânea, 5(n.spe), 183-196.

Gerhardt, T. E, \& Silveira, D. T. (2009). Métodos de pesquisa. Porto Alegre: UFRGS.

Le Boterf, G. (2003). Desenvolvendo a competência dos profissionais (3a ed). São Paulo: Artmed.

Gloria Junior, O. S., Zouain, D. M., \& Almeida, G. O. (2014). Competências e habilidades relevantes para um chefe de unidade descentralizada de perícia da Polícia Federal. Revista de Administração Mackenzie, 15(4), 15-46.

Lima, R. J. C., \& Aragão, S. (2014, novembro). Competências gerenciais no contexto da gestão de projetos: estudo em empresas de grande porte do setor da construção. Anais do Simpósio Internacional de Gestão de Projetos - SINGEP e do Simpósio Internacional de Inovação e Sustentabilidade (S2IS), São Paulo, SP, Brasil, 3, 2.

Luciano, E.M., Becker, C. A., \& Testa, M. G. (2012). Competências indiviuais relevantes para os chief information officers na percepção de profissionais de tecnologia da informação. Revista Eletrônica de Sistemas de Informação, 11(1), 1-25. 
Mello, C. M., Machado, H. V., \& Jesus, M. J. F. (2010). Considerações sobre a inovação em PME'S: o papel das redes e do empreendedor. REA-Revista de Administração da UFSM, Santa Maria, 3(1), 41-57.

Merriam, S. (2009). Qualitative research: a guide to design and implementation. San Francisco: Jossey-Bass.

Neves, J. A. B., Santos, L. M. D., \& Silva, G. M. (2011). Risco de sobrevivência de micro e pequenas empresas comerciais. $R C O$-Revista de Contabilidade e Organizações, $5(11)$, 107 124.

Paiva, K., \& Ferreira, L. (2013). Competências gerenciais na área de tecnologia de informação: um estudo com gestores de empresas localizadas no Triângulo Mineiro. Revista Gestão \& Tecnologia, 13(1), 205-229.

Pena, F. G., Ferreira, A. R. L., Braga, J. O., \& Castanheira, M. E. M. (2015). "Hoje, líder de turma. Amanhã, líder organizacional": um estudo sobre a oportunidade de desenvolvimento de competências aos graduandos em administração. Teoria e Prática em Administração, 5(1), 204-238.

Picchiai, D. (2008). Competências gerenciais: estudo de caso de um hospital público. Cadernos Gestão Pública e Cidadania, 13(52), 19-41.

Quinn, R. E., Thompson, M., Faerman, S. R., \& McGRATH, M. (2003). Competências gerenciais: princípios e aplicações. Rio de Janeiro: Elsevier.

Reichert, F. M., Camboim, G. F., \& Zawislk, P. A. (2015). Capacidades e trajetórias de inovação de empresas brasileiras. RAM-Revista de Administração Mackenzie, 16(5), 161-194.

Santos, L. L. da S., Alves, R. C., \& Almeida, K. N. T. de. (2007). Formação de estratégia nas micro e pequenas empresas: um estudo no centro-oeste mineiro. RAE-Revista de Administração de Empresas, 47(4), 59-73.

Serviço brasileiro de apoio às micro e pequenas empresas. (2014). Participação das micro e pequenas empresas na economia brasileira, 2014. Recuperado em 18 agosto, 2015, de http://www.sebrae.com.br/Sebrae/Portal\%20Sebrae/Estudos\%20e\%20Pesquisas/Participacao \%20das\%20micro\%20e\%20pequenas\%20empresas.pdf

Sparrow, P. R., \& Bognanno, M. (1994). Competency requirement forecast: issues for international selection and assessment. In: C. Mabey, \& P. Iles (Eds.). Managing learning (pp. 57-69). London: Routledge.

Tidd, J., \& Bessant, J. (2013). Managing innovation: integrating technological, market and organizational change (5th ed). John Wiley \& Sons. 